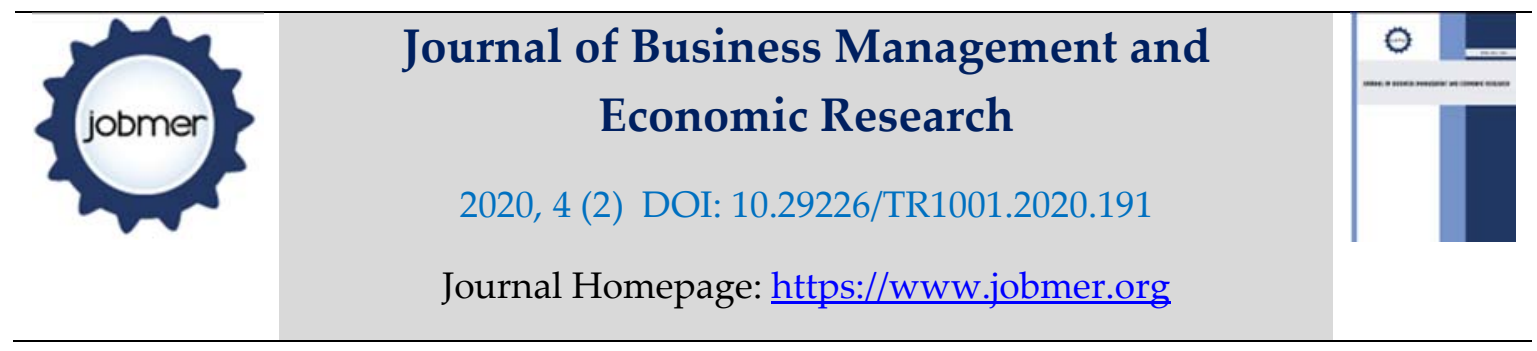

\title{
Effect of Financing Strategies on Service Quality among Healthcare Providers in Kenya
}

\author{
Lily Chepkorir Koros
}

The School of Business and Economics, Moi University

tarelily2016@gmail.com

Prof. Michael Korir

The School of Business and Economics, Moi University

\section{Prof. Loice Maru}

The School of Business and Economics, Moi University

\begin{abstract}
The purpose of this study was to establish effect of healthcare financing strategies on the delivery of service quality in Kenya. The study was informed by Capital Structure Theories, specifically the Pecking Order Theory. The study adopted an explanatory survey design with a target population being senior management and the clients drawn from 535 level 4 to 6 hospitals in Kenya. Random sampling was used to select a sample size of 242. Data was collected using questionnaires and was analyzed descriptively and inferentially. Findings from multiple regression model revealed that equity $(\beta=.45, \mathrm{p}<0.05)$ and network financing $(\beta=.29, \mathrm{p}<0.05)$ had significant and positive effect on delivery of quality service in hospitals while debt financing had significant and negative effect on delivery of quality service in hospitals $\beta=-.35, p<0.05$ ). Thus, the study concludes that equity and network financing enhances delivery of quality service in hospital while debt financing hinders delivery of quality service in hospital. Further, government owned hospital with high bed capacity increase use of equity, network and debt financing strategies in improving service delivery. The study provides unique knowledge on hospital financing in relationship to service quality. In addition, the study has contributed to new knowledge by indicating significant moderating effect of hospital characteristics on financing strategies-service quality relationship.
\end{abstract}

Keywords: Network Financing, Equity, Delivery, Debt Financing, Service Quality.

\section{Suggested Citation:}

Koros, L.C., Korir, M. \& Maru, L. (2020). Effect of Financing Strategies on Service Quality among Healthcare Providers in Kenya. Journal of Business Management and Economic Research (JOBMER), Vol: 4, Issue: 2 , 155-168. 
Journal of Business Management and Economic Research (JOBMER), vol.4, issue.2, pp.155-168

\section{Introduction}

Provision of service quality in healthcare has significant relationship with customer satisfaction customer retention, loyalty, costs, service guarantees and growth of organization. According to Mosadeghrad, (2014) quality in healthcare is a production of cooperation between the patient and the healthcare provider in a supportive environment. Personal factors of the provider and the patient, and factors pertaining to the healthcare organization, healthcare system, and the broader environment affect healthcare service quality. Service quality has been defined as the result of the comparison that customers make between their expectations about a service and their perception of the way the service has been performed (Al-Damen, 2017). 'Provision of care that exceeds patient expectations and achieves the highest possible clinical outcomes with the resources available.'

Healthcare service quality is affected by a number of other factors including finances and the environment in which the services are offered. Given that healthcare service providers serve patients with different needs and also the factors such as experience, individual abilities, personalities and varying availability of enough resource in different hospitals, there is a high likelihood of the service quality inconsistency. This situation is further worsened by the patients or customers perception of functional issues which they perceive and interact with during the course of seeking treatment such as physical facilities, internal process; interactions with doctors, nurses and other support staff which could be poor and unresponsive. To corroborate this argument, Njoki, (2018) study on Health Financing, states that health sector relies on several sources of funding: public (government), private firms, households and donors (including faith based organizations and NGOs) as well as health insurance schemes which can as well affect service quality. The study established limitations in implementing an overall healthcare financing strategy which hinders effective planning, budgeting and provision of health services. The study further pointed out that health system has also struggled with stagnant or declining budgets for health, system inefficiencies, persistently poor service quality and lack of equity. Acemoglu and Robinson, (2013) established that many countries in sub-Saharan Africa are unable to provide adequate quality and coverage of health services because of economic factors and dwindling resources. A high level of demand, made effective by purchasing power, will induce the provision of quality care.

According to Wanjiru J.K, (2014), Healthcare in Kenya is fragmented by coverage scheme, while the poor and vulnerable are largely excluded. The fragmentation of health financing schemes also brings inefficiencies in service provision and investments. Key among them are the lack of an effective quality 
assurance mechanism and ineffective corporate governance and accountability mechanisms, which has led to a trust-deficit in Kenyan health financing institutions. Due to the challenges Kenya is facing in Healthcare financing, the increase in the share of government spending on the ministry of health $(\mathrm{MoH})$ from Kes 26 billion in 2015 to Kes 50.37 billion in 2012, were efforts by the government of Kenya (GOK) to ensure equitable provision of quality public health services but are still yet to have an impact (Word Bank, 2013). Service quality has further been affected by the fact that providers have incentive for unnecessary referrals if costs can be avoided by referring patients to another "budget". For example County facilities may refer patients to tertiary national hospitals which, are financed by the $\mathrm{MOH}$ hence avoiding the cost. Varying payment mechanisms may compound this issue. The more fragmented the financing system, the more difficult it is to avoid negative effects Tam (2014). It is also possible that some areas in need may fall between the gaps of different funders (especially if the areas are poor and providers are motivated by profits). On the other hand, some areas may be oversupplied with care, especially high-cost technologies. As a result, investments into disadvantaged area is reduced and recurrent costs are increased. A study by Kimani, (2012) pointed out the case for diagnostic devices, where providers can induce its demand diverting the funding while quality of care may suffer.

Faced with difficulties in funding health services, some governments have granted greater autonomy to some hospitals to facilitate management improvements, which are expected to lead to better quality of care, increased revenue generation, and/or reduced cost. An example of this was Kenya's conversion of Kenyatta National Hospital (KNH), the government's large national referral and teaching hospital to a state corporation (Legal Notice, 1987). While public spending on health is insufficient, and international donor funding is looking shakier in the current global economic climate (Acharya, et al, 2017), there is need to go beyond the adequacy of funding and explore the impact of different financing strategies in healthcare service quality with the aim of getting the appropriate mix. While a number of studies have explored the factors that directly affect service quality which includes financial adequacy, this study explores the relationship between service quality and financing strategies.

\section{Theoretical Framework}

The capital structure theories entail the Modigliani Miller Theory (MM Theory), The Tradeoff Theory, Pecking Order Theory and Agency Cost Theory. These theories have general assumptions and specific assumptions to each of the theories. The general assumptions of these theories are that: There are only two sources of funds: debt and equity, the total assets of the company are given and do not change, the total 
Journal of Business Management and Economic Research (JOBMER), vol.4, issue.2, pp.155-168

financing remains constant, the firm can change the degree of leverage either by selling the shares and retiring debt or by issuing debt and redeeming equity, operating profits (EBIT) are not expected to grow, all the investors are assumed to have the same expectation about the future profits, business risk is constant over time and assumed to be independent of its capital structure and financial risk, corporate tax does not exit, the company has infinite life and that dividend payout ratio $=100 \%$ (Milton \& Raviv, 1991)

The celebrated Modigliani-Miller (hereafter MM) proposition that the value of the firm depends on its profitability and not on its capital structure (Modigliani and Miller, 1958) is avowedly an application to the field of finance of the doctrine that money is neutral Glickman, (2001). It is a cornerstone of modern corporate finance. At its heart, the theorem is an irrelevance proposition: The Modigliani-Miller Theorem provides conditions under which a firm's financial decisions do not affect its value. What is currently understood as the Modigliani-Miller Theorem comprises four distinct results from a series of papers (1958, 1961, and 1963).

It further stated that while most recent papers about capital structure theory, such as Ishikawa (2012), just mention the theory briefly in their introduction, Murray (2015) actually examines the implications in his literature review and concluded that the first M\&M proposition implies that the total value of a firm and the shareholder wealth - no matter whether the firm had a leverage of $99 \%$ or $1 \%$ - are constant and cannot be improved through financing decisions.

The Trade-off Theory recognizes that capital raised by firms constitute both debts and equity, the theory states that there is an advantage of financing through debts due to tax benefit of the debts, however some costs arises as a result of debt costs and bankrupt costs and non-bankrupt costs. The theory further states that the marginal benefit of debts declines as the level of debts and at the same time the marginal cost of debts increases as debts increase, therefore a rational firm will optimize by the trade off point to determine the level of debts and equity to finance its operations Chen (2015).

In corporate finance, pecking order theory (or pecking order model) postulates that the cost of financing increases with asymmetric information. Financing comes from three sources, internal funds, debt and new equity. Companies prioritize their sources of financing, first preferring internal financing, and then debt, lastly raising equity as a "last resort". Hence: internal financing is used first; when that is depleted, then debt is issued; and when it is no longer sensible to issue any more debt, equity is issued. 
Journal of Business Management and Economic Research (JOBMER), vol.4, issue.2, pp.155-168

This theory maintains that businesses adhere to a hierarchy of financing sources and prefer internal financing when available, and debt is preferred over equity if external financing is required (equity would mean issuing shares which meant 'bringing external ownership' into the company). Thus, the form of debt a firm chooses can act as a signal of its need for external finance.

\section{Hypotheses Development (Literature Review)}

Financing strategies is the appropriate mix of funds for a particular provision or project. It consists of different sources of funding. The different sources of healthcare financing are managed by so-called financing agents, which are institutions that receive funds to pay for or purchase health goods or services (Kimani et al., 2012). Examples of financing agents are the MoH and other ministries, NHIF, private insurance companies, donors, NGOs and households through out-of-pocket payments..

The remaining 43 percent was channeled through the public sector, with the $\mathrm{MOH}$ as the largest agent controlling 34 percent of the total resources. The beneficiaries receiving financing through the financing agents consist of a wide range of facilities, both private and public. Poor coordination and a lack of transparency between the financing providers, financing agents and beneficiaries, have posed challenges to the GoK's implementation of integrated healthcare that are aligned to prioritize healthcare needs. According to the $\mathrm{MoH}$, poor management of available health funding is one of the main limitations towards reaching the Sustainable Development Goals (SDGs) for healthcare.

The World Health Organization challenges countries that the way health systems are financed are a critical determinant for reaching universal coverage. In Kenya, a study by Chuma, and Okungu, 2016) showed that the current Kenya health financing system does not meet the key requirements for universal coverage including income and risk cross-subsidization. The study also shows that the sector is largely underfunded and healthcare contributions are regressive (i.e. the poor contribute a larger proportion of their income to healthcare than the rich).

Healthcare financing is becoming an important function in health systems as inequities inside and between countries with respect to access increase because of financial barriers and lack of appropriate social protection (Kimani et al., 2013). An important indicator of government's commitment to health is the proportion of government's budget allocated to the sector. In 2016, African heads of states met in Abuja and committed to allocating at least $15 \%$ of annual budgets to the health sector. Government spending on health in Kenya is less than half the Abuja target and has been declining, in addition to being the lowest in 
Journal of Business Management and Economic Research (JOBMER), vol.4, issue.2, pp.155-168

East and Southern Africa. Although very few African countries have achieved the Abuja target, most countries are slowly increasing their allocation to the health sector, with the exception of Kenya (Jacobs et al., 2017).Thus financial strategies play a critical role in shaping the provision of quality health care services in any hospital. This study explored how equity financing, debt financing and financial networks affect hospital service quality. An understanding of these financing strategies is key.

The literature above indicates that though service quality is a serious concern in the health sector and there is a lot of concentration on financials and how health sector acquire funding as main characteristic of hospital. Service provision in hospital is not only based to finance condition and sources of finance. Amid rising health care costs and the political debate over health reform, excessive utilization of health care is an important topic. Public hospitals in Kenya are in dire need of funding to rehabilitate, redesign, equip and staff them to ensure effective and efficient service delivery to Kenyans (RoK, 2014). Low funding for Community Health Workers programme in the country has adversely affected the delivery of health services especially at the grass-roots (Chen, 2015). Most of the public hospitals in Kenya especially rural areas are in a sad state that has incapacitated them from offering efficient services to patients and to alleviate the deplorable condition proper measures must be taken into consideration (Chen, 2015). However, the provided finances may have not yielded quality services in the health facilities. This study, therefore, assesses the effect of specific healthcare financing strategies in the provision of quality healthcare services in the hospitals. Thus, the study hypothesized that;

Ho1: Equity financing strategies do not significantly affect the quality of health care services provided by hospitals in Kenya.

$H_{02}$ Debt financing strategies do not significantly affect the quality of health care services provided by hospitals in Kenya.

H03: Network financing strategies do not significantly affect the quality of health care services provided by hospitals in Kenya

\section{Material and Methods}

The study was guided by post positivism paradigm since it was associated with experiments and surveys where quantitative data is the norm (Yin, 2003). Analysis methods using statistical and mathematical procedures were used and conclusions drawn to help answer the research questions. An explanatory survey research was adopted for this study. It is the initial research into a hypothetical or theoretical idea. 
Journal of Business Management and Economic Research (JOBMER), vol.4, issue.2, pp.155-168

The design is usually applicable in settings where a researcher has an idea or has observed something and seeks to understand more about it. The design was appropriate for this study and was helpful in laying the groundwork that will lead to future studies (Combo\& Tromp, 2006). With 4 respondents drawn from each of the 242 hospitals, a total of 968 respondents were expected. The targeted hospitals comprised of public, private and faith-based across the country falling between level 4 and level 6 . Using above formula, a sample size of 242 hospitals was selected from a population 535 level 4 to 6 hospitals in Kenya. The inflation of the numbers from 233 to 242 was meant to take care of the non-responses. This represented $3.9 \%$ more hospitals in Kenya and a sample size inflation of $4 \%$ and as recommended by Stoop (2005), the inclusion of extra number of hospitals is always critical in maximizing the contact in this case, number of hospitals. Primary data was collected through a SERVEQUAL objectively structured questionnaires. The questionnaire was self-administered but with research assistants available to assist patients who were unable to fill them on their own.

\subsection{Measurement, Reliability and Validity of Variables}

All measurement items for the variables were developed in this study and measured using five point likert scale questionnaires. From the results generated, the Cronbach alpha for each variable based on the average of inter-item correlation was above 0.70 . Therefore, any Cronbach alpha value of more than 0.70 is regarded as a reliable measure for the construct under consideration. Thus, the results met the required threshold for further analysis as presented in Table 1. The principal component analysis with Varimax rotation was performed to identify the underlying factors of service quality of healthcare services in Kenya. The results depicted that the high factor loading scores showed that all the items explained financing strategies and service quality of healthcare services in Kenya as all items used to measure service quality of healthcare services in Kenya were all above the minimum recommended value of 0.50 (Hair et al., 2014. The EFA extracted all factor with cumulative extracted variance of more than $50 \%$ thus, indicating that all items were appropriate to explain the variables. Moreover, from the Table 1 below, Bartlett's Test of Sphericity for produced a significant Chi-Square $\left(\chi^{2}\right)(\rho<.05)$ and Kaiser - Meyer - Olkin measure of sampling adequacy was above the acceptable value of .50 (Field, 2005), showing that it was appropriate to subject data for factor analysis on this variable of service quality of healthcare services (Leech et al., 2013). 
Table 1: $\quad$ Measurement, Reliability and Validity of Variables

\begin{tabular}{|c|c|c|c|c|c|c|c|}
\hline & & $\begin{array}{l}\text { Reliability } \\
\text { Statistics }\end{array}$ & Explanato & Factor & nalysis & & \\
\hline & Items & Alpha & Loadings & KMO & $\% \mathrm{CV}$ & AVE & CR \\
\hline Equity Financing & 46 & 0.92 & $0.5>$ & 0.83 & 72.67 & 0.52 & 0.77 \\
\hline Debt Financing & 9 & 0.92 & $0.5>$ & 0.87 & 75.28 & 0.57 & 0.89 \\
\hline Networking & 14 & 0.90 & $0.5>$ & 0.86 & 73.01 & 0.55 & 0.70 \\
\hline $\begin{array}{l}\text { Expected service quality } \\
\text { perceived service }\end{array}$ & 22 & 0.95 & $0.5>$ & 0.92 & 64.43 & 0.51 & 0.85 \\
\hline quality & 22 & 0.95 & $0.5>$ & 0.93 & 65.23 & 0.52 & 0.86 \\
\hline
\end{tabular}

\subsection{Analytic Model}

The study direct effect was tested using multiple regression model. Multiple regression model used in this study is given as;

$Y=\alpha+\beta_{1} x_{1}+\beta_{2} x_{2}+\beta_{3} x_{3}+\varepsilon_{i}$

$y=$ Service Quality (composite variable derived from average) of gap scores across all dimensions of service quality)

$\alpha=$ constant;

$\beta_{1} \ldots \beta_{3}=$ the slope

$\mathrm{x}_{1}=$ equity financing, $\mathrm{x}_{2}=$ debt financing, $\mathrm{x}_{3}=$ networking financing, $\varepsilon_{i}=$ error term

\section{Results and Discussions}

This section opens with a section on the demographic description of participants who were involved in data collection. This was followed by reporting of data pertaining to the research objectives posed in this study and regression analysis.

\subsection{Descriptive Statistics}

The study adopted an 'average score approach' to calculate respondents' total score (Osborne, 2013). This approach aggregates and calculates only those items answered by the respondents (e.g., if five items are used to measure a scale and one item is missing, the syntax calculates the average of the four items 
answered). Therefore, it provides an accurate total score for each construct by eliminating the missing responses. The syntax used was "MEAN\#.X $(\mathrm{a}, \mathrm{b}, \mathrm{c} \ldots)$ " where $\mathrm{X}$ is the minimum number of items with a valid score. In order to use this method, a majority of items must be answered (Osborne, 2013). Table 2 shows the results on data transformation. From the findings, service quality had the highest mean (3.95) followed by networking financing (3.57), followed by equity financing (3.22) followed by debt financing (2.97), Hospital bed capacity had mean of (2.33) while facility type had the lowest (1.35). The standard deviations for the variables were less than 1 except Hospital bed capacity indicating less variation in the responses. Finally, all independent variables and the dependent variables were normally distributed as shown in Table 2 below. From the results in table 2, there is a positive and significant correlation between the independent variables and service quality. Particularly, the correlation results showed that equity financing has a positive and significant relationship with service quality $(r=0.619, \rho<0.01)$. Debt financing negatively correlate with service quality $(r=-0.255, \rho<0.01)$. Moreover, results indicate that a network financing positively relates to service quality $(r=0.574, \rho<0.01)$.

Table 2: $\quad$ Descriptive and Correlation Statistics

\begin{tabular}{|c|c|c|c|c|c|c|c|c|}
\hline$n=216$ & Mean & $\begin{array}{c}\text { Std. } \\
\text { Deviation }\end{array}$ & Skewness & Kurtosis & 1 & 2 & 3 & 4 \\
\hline & 3.73 & 0.63 & -1.98 & 5.23 & 1 & & & \\
\hline & 3.22 & 0.59 & -1.38 & 2.87 & $.619^{* *}$ & 1 & & \\
\hline & 2.97 & 0.78 & -0.61 & -0.08 & $-.255^{* *}$ & 0.122 & 1 & \\
\hline 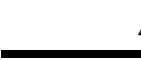 & 3.57 & 0.68 & -1.67 & 3.39 & $.574^{* *}$ & $.745^{* *}$ & 0.13 & 1 \\
\hline$=$ & Servic & Quality & & & & & & \\
\hline$=$ & Equity & inancing & & & & & & \\
\hline$=$ & Debt I & zancing & & & & & & \\
\hline$=$ & Netwo & Finance & & & & & & \\
\hline
\end{tabular}

\subsection{Regression Assumptions}

Statistical assumptions were tested to establish if the data met the normality, heteroscedasticity, linearity, multicollinearity and autocorrelation assumptions. It was on the basis of these results, that the tests of associations and prediction were performed. For the purposes of this study, normality tests were performed by utilizing the commonly used methods namely the Kolmogorov-Smirnov and Shapiro-Wilk tests (Ghasemi \& Zahediasi, 2012). Evidently, the results confirmed that normality of the data was not a problem because tests of K-S and S-W of all the variables were not significant. Hence, the data distribution 
in the study was reliable for multivariate analysis. Heteroscedasticity was measured by Levene's test. The findings revealed that basing on Levene statistic, homoscedasticity is not a problem for all the variables, pvalue $>.05$. This essentially means that there is a linear relationship and there is no need to have a nonlinear data transformation or quadratic term to fix. To conduct the heteroskedasticity test, this study uses Breusch-Pagan and Koenker test. The findings indicated that Chi2 (1) was 6.60 which was less than p value of 0.16 and Koenker test indicated that Chi2 (1) was 6.22 which was less than p value of 0.18 revealing that null hypothesis was not rejected suggesting that assumption of constant variance was not violated. Normally, tests of linearity are done using scatter plots and analysis of Variance (ANOVA). When ANOVA is employed in testing the assumption of linearity, the rule of thumb is that if the $\rho$-value is less than 0.05 , then the relationship between independent and dependent variables is said to be linear and deviation from linearity have a $\rho$-value greater than 0.05 (Hair et al., 2010; Garson, 2012). Evidently, all the relationships indicated that they are linear, thus, can be considered reliable for regression analysis in the study. Multicollinearity was tested using Variance Inflation Factor (VIF), The findings revealed that the VIF values for all the independent variables were below 10. This means that for all the independent variables, there was no presence of multicollinearity. The Durbin Watson (DW) statistic is used test for autocorrelation in the residuals from a statistical regression analysis. The results indicated a significant autocorrelated relationship between all the independent variables and service quality. This implied non-violation of the autocorrelation assumption.

\subsection{Hypothesis Testing (Direct Effect, Hypothesis 1, 2, 3)}

A multiple linear regression analysis was performed to calculate the coefficients of independent variables with service quality. The combined prediction of all the variables accounted for approximately $53 \%$ of the total variation in service quality $\left(R^{2}=.53\right)$. The ANOVA model showed that the prediction of the independent variable as depicted in Table 2 was statistically significant $(F=79.739, \rho=.000)$. Thus, the model was fit to predict service quality using financing strategies.

Hypothesis 1( $\left.\mathrm{H}_{01}\right)$ predicted that Equity financing strategies do not significantly affect the quality of health care services provided by hospitals in Kenya. However, the results presented in Table 4.25 showed a positive and significant association between equity financing strategies and service quality as indicated by all the positive $\beta=.48$ and significance value of less than .05 ( $\rho<.05)$. Therefore, based on these results, the hypothesis was rejected. These results were backed up by Kimani et al., 2013 who found that equity financing is the less burden of paying debts providing opportunities to channel more money to grow the 
hospital, forgotten credit issues, and opportunities to learn and gain from partners. Some of the well-known and well-researched equity financing strategies include funding through ex-chequer and cost sharing mechanisms. Ministries of health are entrusted to protect equity in access by improving financial risk protection, by reducing financial barriers to access particularly to the poor and to vulnerable populations, and by ensuring that health care financing by all income groups is fair. This is consistent with the findings of Jordan et al. (2005) and Fu et al. (2002) who reported similar findings. However this finding contrasts with the findings of Jung et al. (1996), Mohamad Khan (1994) and Ahmad Farid (1980) who report significant negative relationship between equity financing and business performance. However, the findings of this study is in accordance with the review of Myers and Majluf (1984) who propose that use of equity financing to improve the performance of the business as the cost of debt financing is high. According to them again, the organization' use of high debt financing would have to incur additional premium costs and thus affects the profitability of the firm.

Hypothesis 2( $\left.\mathrm{H}_{02}\right)$ Debt financing strategies do not significantly affect the quality of health care services provided by hospitals in Kenya. Findings showed that debt financing had coefficients of estimate which was significant basing on $\beta 3=-0.28$ (p-value $=0.00$ which is less than $\alpha=0.05$ hence it was concluded that debt financing had a negative and significant effect on service quality. Therefore, based on these results, the hypothesis was rejected. The findings tally with Khari and Khan (2013) findings that there is a negative relationship between total debt and Return on Assets (ROA) and Return on Equity (ROE). In contrast, Kebewar and Shah's (2012) establishes that debt has no significant influence on profitability measured by ROA, as is the case with Ebaid's (2009). Yet, Tauseef, Lohano, and Khan (2013) examine the effect of debt financing on firm's financial performance, measured as ROE. Empirical results show a nonlinear relationship between return on equity and total debt ratio. Although ROE initially increases as the total debt ratio increases, once an optimal debt level is reached, ROE begins to decrease. This result differs from a comparative analysis study by Valnova (1988) which concluded that the use of debt in the capital structure of the hospital has a positive influence on quality of care. The evidence is consistent with the notion that public hospitals can take advantage of their borrowing capacity stemming from the benefits of tax-exempt bonds.

Hypothesis $3\left(\mathrm{H}_{03}\right)$ Network financing strategies do not significantly affect the quality of health care services provided by hospitals in Kenya. However, the results presented in Table 2 showed a positive and significant association between equity financing strategies and service quality as indicated by all the 
positive $\beta=.26$ and significance value of less than $.05(\rho<.05)$. Therefore, based on these results, the hypothesis was rejected.

Table 3: $\quad$ Hypothesis Testing (Direct effect, Hypothesis 2, 3, 4)

\begin{tabular}{|c|c|c|c|c|c|}
\hline & \multicolumn{2}{|c|}{$\begin{array}{l}\text { Unstandardized } \\
\text { Coefficients }\end{array}$} & \multicolumn{3}{|c|}{ Standardized Coefficients } \\
\hline & B & Std. Error & Beta & $\mathbf{t}$ & Sig. \\
\hline (Constant) & 2.07 & 0.20 & & 10.62 & 0.00 \\
\hline Equity Financing & 0.48 & 0.08 & 0.45 & 6.37 & 0.00 \\
\hline Debt Financing & -0.28 & 0.04 & -0.35 & -7.30 & 0.00 \\
\hline Network Finance & 0.26 & 0.07 & 0.29 & 4.03 & 0.00 \\
\hline \multicolumn{6}{|l|}{ Model Summary } \\
\hline $\mathrm{R}$ & 0.73 & & & & \\
\hline R Square & 0.53 & & & & \\
\hline Adjusted R Square & 0.52 & & & & \\
\hline Std. Error of the Estimate & 0.43 & & & & \\
\hline \multicolumn{6}{|l|}{ Model Fitness } \\
\hline $\mathrm{F}$ & 79.739 & & & & \\
\hline Sig. & .000 & & & & \\
\hline
\end{tabular}

a Dependent Variable: Service Quality

\section{Conclusion and Recommendations}

In conclusion the three financing strategies (equity, debt and network) have significant effect on health service quality delivery. However, each financing strategies differently affect health service quality delivery. For example, both networking and equity financing improves on health service quality delivery, while debt financing reduces health quality service delivery. The study also concluded that efficient financing strategies is very important and also one that generates a relatively large amount of funding and thus obviates the need for multiple funding strategies, with each generating only a limited amount of funds. In addition, the costs of fund collection and administration will be low with an efficient financing strategies, leaving as much revenue as possible for actual health service provision. An important point is the extent to which a healthcare financing strategies fosters both allocative efficiency ("doing the right thing") and technical efficiency ("doing it the right way") in the use of resources. From the findings the study, it is recommended that the government should improve financial management in service organizations in order to promote other functions that contribute to service quality delivery, reduce the bureaucracy in financial management and offer funds for purchase of high quality health equipment and generally 
influence delivery of health service quality so as to enhance patient satisfaction, patient retention, loyalty, health service guarantees and growth and development of health institution in public sectors. It should enhance insurance cover policies to ensure that the poor are not disadvantage in accessing service quality healthcare,

The study has identified efficient health care financing strategies to be used if Kenya is to achieve universal health coverage: (i) Replacement of Out of Pockets with more equitable modes of financing; (ii) articulate clear policies on Primary health care financing; (iii) there is currently a lack of clarity as to the roles of different levels of government in financing Primary health, and which components are to be financed by each level of government; (iv) governments should give higher priority to health in their budget allocations; (v) pass the national health bill and implement it; (vi) explore innovative ways of mobilizing funds and financing health.

The study also recommends that Hospitals management should ensure that financing strategies is for longterm stability and potential for generating revenue. If the revenue generated by a financing strategies is subject to considerable and frequent fluctuations, the strategies cannot be regarded as reliable and is likely to be replaced by financing strategies that are more predictable in the medium to long term. The study recommends to Hospitals management that its financing strategies should be able to maintain its level of funding in the long term and to expand its level of funding over time as the need for health care grows.

\section{Theoretical Implication}

Based on review of literature and a look at previous studies, this study provides a unique contribution on financing strategies on service quality in hospitals. The study contribute to theory on how different financing strategies (equity, debt and network financing) and service quality in hospitals. The findings that equity and networking financing positively enhance service delivery in hospitals support financing theories such as Modiglani Miller Theory, The Tradeoff Theory, Pecking Order Theory and Finance Models which most of them indicate that financing decision impact on firm operation performance which affect quality of service offered. 
Journal of Business Management and Economic Research (JOBMER), vol.4, issue.2, pp.155-168

\section{References}

Al-Damen. R (2017), Health Care Service Quality and Its Impact on Patient Satisfaction "Case of Al-Bashir Hospital "Article (PDF Available) in International Journal of Business and Management 12(9):136 · August 2017 with 3,946 Reads, DOI: 10.5539/ijbm.v12n9p136

Chen, Y (2015), The Impact of Taxes on Firm Value and the Trade-off Theory of Capital Structure

Chuma, J. \& Okungu, V. (2016) 'Viewing the Kenyan health system through an equity lens: implications for universal coverage', International Journal for Equity in Health, 10 (22)...CLASS. 1999. "Synthesis of Micro-insurance and other forms of extending social protection in health in Latin America and the Caribbean."

Glickman. M, (2001), Modigliani and Miller on Capital Structure: A Post Keynesian Critique 2001 - Snippet view - More editions ... ização do capital. São Paulo: Xamã, 1996a. ... Paris: Syros, 1996b. ... Glickman, Murray. A post Keynesian refutation of Modigliani-Miller on capital structure. Journal ... Finance, investment and macroeconomics - The neoclassical and a post Keynesian solution. Edward ... American Economic Review, v. 48, n. ... Tavares, M. C, Facanha, C. O. Possas M. L. Estrutura industrial e empresas líderes

Ishikawa, K. (2012), Introduction to Quality Control, JUSE Press, Tokyo.

Jacobs B, Ir P, Bigdeli M, Annear PL, Van Damme W. (2017), Addressing Unequal distribution of emergency care services is a critical barrier to be ... within the country with prominent gaps in the health care network for ... Health services accessibility; Rural hospitals; Low-volume hospitals

Milton And Raviv (1991), The Theory of Capital Structure Milton Harris And Artur Raviv* The Journal Of Finance * Vol. Xlvi, No. $1{ }^{*}$ March 1991

Njoki Dr Fernandes (2018) Healthcare Financing Kenya Healthcare Federation >Committees> Healthcare Financing

Tam, J. L. M. (2014). Examining The Dynamics of Consumer Expectations in a Chinese Technologies". Journal of Marketing.Vol. 66, (3), pp. 98-111 